\title{
A Novel Method to Value Real Options in Health Care: The Case of a Multicohort Human Papillomavirus Vaccination Strategy
}

\author{
ARTICLE in CLINICAL THERAPEUTICS · JUNE 2013 \\ Impact Factor: 2.73 · DOI: 10.1016/j.clinthera.2013.05.003 Source: PubMed
}

CITATIONS

6

5 AUTHORS, INCLUDING:

\section{Giampiero Favato}

Kingston University London

54 PUBLICATIONS 127 CITATIONS

SEE PROFILE

\section{Andrea Marcellusi}

University of Rome Tor Vergata

64 PUBLICATIONS 172 CITATIONS

SEE PROFILE

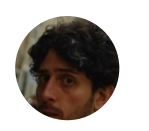

Gianluca Baio

University College London

90 PUBLICATIONS 628 CITATIONS

SEE PROFILE

Francesco Saverio Mennini

University of Rome Tor Vergata

85 PUBLICATIONS 241 CITATIONS

SEE PROFILE 


\section{A Novel Method to Value Real Options in Health Care: The Case of a Multicohort Human Papillomavirus Vaccination Strategy}

Giampiero Favato, $\mathrm{DBA}^{1}$; Gianluca Baio, $\mathrm{PhD}^{2,3}$; Alessandro Capone, $\mathrm{MD}^{1}$; Andrea Marcellusi, $\mathrm{MSc}^{4}$; and Francesco Saverio Mennini, MSc ${ }^{1,4}$

${ }^{1}$ Institute of Leadership and Management in Health, Kingston University, London, United Kingdom; ${ }^{2}$ Department of Statistical Science, University College, London, United Kingdom; ${ }^{3}$ Biostatistics Unit, Department of Statistics and Quantitative Methods, University of Milano-Bicocca, Milan, Italy; and ${ }^{4}$ Economic Evaluation and HTA (EEHTA), Faculty of Economics, University of Tor Vergata, Rome, Italy

\section{ABSTRACT}

Background: A large number of economic evaluations have already confirmed the cost-effectiveness of different human papillomavirus (HPV) vaccination strategies. Standard analyses might not capture the full economic value of novel vaccination programs because the cost-effectiveness paradigm fails to take into account the value of active management. Management decisions can be seen as real options, a term used to refer to the application of option pricing theory to the valuation of investments in nonfinancial assets in which much of the value is attributable to flexibility and learning over time.

Objective: The aim of this article was to discuss the potential advantages shown by using the payoff method in the valuation of the cost-effectiveness of competing HPV immunization programs.

Methods: This was the first study, to the best of our knowledge, to use the payoff method to determine the real option values of 4 different HPV vaccination strategies targeting female subjects aged 12, 15, 18, and 25 years. The payoff method derives the real option value from the triangular payoff distribution of the project's net present value, which is treated as a triangular fuzzy number. To inform the real option model, cost-effectiveness data were derived from an empirically calibrated Bayesian model designed to assess the cost-effectiveness of a multicohort HPV vaccination strategy in the context of the current cervical cancer screening program in Italy. A net health benefit approach was used to calculate the expected fuzzy net present value for each of the 4 vaccination strategies evaluated.

Results: Costs per quality-adjusted life-year gained seemed to be related to the number of cohorts targeted: a single cohort of girls aged 12 years (€10,955 [95\% CI, $-1,021$ to 28,212$]$ ) revealed the lowest cost among the 4 alternative strategies evaluated. The real option valuation challenged the costeffectiveness dominance of a single cohort of 12-yearold girls. The simultaneous vaccination of 2 cohorts of girls aged 12 and 15 years yielded a real option value $(€ 17,723)$ equivalent to that attributed to a single cohort of 12-year-old girls (€17,460).

Conclusions: The payoff method showed distinctive advantages in the valuation of the cost-effectiveness of competing health care interventions, essentially determined by the replacement of the nonfuzzy numbers that are commonly used in cost-effectiveness analysis models, with fuzzy numbers as an input to inform the real option pricing method. The real option approach to value uncertainty makes policy making in health care an evolutionary process and creates a new "space" for decision-making choices. (Clin Ther. 2013;:!Un-mu) (c) 2013 Elsevier HS Journals, Inc. All rights reserved.

Keywords: human papillomavirus, multicohort, real option, vaccination, valuation.

\section{INTRODUCTION}

Invasive cervical cancer is a major threat to women's health and accounts each year for $>500,000$ new cases and 275,000 deaths worldwide. ${ }^{1}$ The oncogenic

Accepted for publication May 8, 2013.

http://dx.doi.org/10.1016/j.clinthera.2013.05.003

0149-2918/\$ - see front matter

(c) 2013 Elsevier HS Journals, Inc. All rights reserved. 
strains of the human papillomavirus (HPV) are now conclusively recognized as the etiologic cause of cervical cancer and other malignant genital tumors. ${ }^{2-4}$ Since the earliest approvals of anti-HPV vaccines in 2006, access to the HPV vaccination program has become a critical priority for public health authorities worldwide. The main benefit of an expanded HPV vaccination program would be a significant reduction in the HPV infection rate, with a consequent decrease in the incidence and mortality rate of HPV-induced malignancies. Although the vaccination of all women for whom HPV vaccines are indicated (those aged 9-26 years) would be the most equitable approach, it might not be cost-effective. A large number of economic evaluations have already confirmed the cost-effectiveness of different vaccination strategies. ${ }^{5-14}$ However, standard economic analyses might not capture the full economic value of novel vaccination programs ${ }^{15}$ because even the most sophisticated cost-effectiveness models are ultimately conducible to the accounting paradigm of the net present value (NVP). The NPV is the difference between a singlepoint discounted mean value for cash inflows and a single-point discounted mean for cash outflows, including the initial investment. The NPV decision rule is simple: assuming that cash inflows and outflows have been discounted at the opportunity cost (usually, but not necessarily, the cost of capital), we should accept the investment if the NPV is positive. When comparing 2 or more exclusive investments, all having positive NPV, the 1 with highest NPV should be accepted. ${ }^{16}$ An important criticism of NPV analysis is that it fails to take into account the value of active management. Active management aims to produce valuable information, thereby reducing uncertainty over the future. Furthermore, subsequent to making an investment, management can revise operating plans that underlay an original NPV forecast, such as altering input and output mixes or shutting down plants temporarily to maximize operating cash flows. Thus, active management can affect a project's value, but it is not accounted for in conventional NPV analysis. By leading an investment from beginning to end, management may be able to squeeze its cash flow distribution toward a higher rate of return. ${ }^{17}$ This method has led to the development of the idea that because management control can affect a project's payoff in terms of potential profits and losses, control opportunities can be seen as being analogous to financial options and, therefore, may be analyzed by using options pricing theory. ${ }^{18}$ Real option valuation is treating the different types of managerial flexibility as options and valuing them with option pricing models.

The logic of option pricing is straightforward: the value of an option is the present value of the chance of occurrence-weighted distribution of the positive future option values, while mapping the negative values as zero. The reason for considering the negative values of the future option value distribution as zero is that the holder of the option has the right, but not the obligation, to exercise the option contract. The holder will not exercise if it would cause a loss but exercises only if profit is created, thus making the downside zero at maximum. Such options and the calculation of their potential value would not be included in the usual NPV analysis. The fuzzy payoff method for real option valuation is a new method for valuing real options, based on the use of fuzzy logic and fuzzy numbers for the creation of the payoff distribution of an investment. ${ }^{19}$

This was the first study, to the best of our knowledge, to use the payoff method to determine the real option values of 4 different HPV vaccination strategies, targeting female subjects aged 12, 15, 18, and 25 years. The aim of the article was to discuss the potential advantages shown by the payoff method in the valuation of the costeffectiveness of competing HPV immunization programs.

\section{METHODS \\ Background Procedure}

Before discussing the real option valuation, 3 critical methodologic questions must be addressed ${ }^{20}$ :

1. When is there a real option embedded in the investment decision?

After making an investment decision in health care (eg, to initiate a national vaccination program), policy makers can continuously monitor the actual costs and benefits over time and terminate the program if its incremental cost-effectiveness ratio (ICER) falls below a commonly accepted maximum threshold. This option is valuable because it limits the losses that could be accumulated over time without management intervention, whereas the calculation of its potential value would not be included in the usual NPV framework, which assumes that the program would continue for the estimated length of its life. Moreover, management can decide to change the implementation choices made ex ante, on the basis of information that only became available after the investment decision. As an example, when the chosen vaccine becomes 
available at a price lower than anticipated, as an effect of market competition, the coverage rate can be extended to maximize the economic benefits of the budget allocated to HPV immunization. ${ }^{21}$

2. When does the option have significant economic value?

In a perfectly competitive market, no option will generate positive NPV because it can be easily duplicated by anyone. At the limit, real options are most valuable when the owner of the option has market exclusivity. In the case of a national immunization program, we can assume that the payer (the Italian National Health Service [NHS]) has exclusivity on the implementation of the HPV vaccination.

3. Can the real option value be estimated by using an option pricing model?

Real options are most commonly valued with the Black-Scholes option pricing formula ${ }^{22}$ or the binomial option valuation method. ${ }^{23}$ These 2 models are based on the assumption that the processes they use to model the markets of the underlying asset can accurately create a correct probability distribution of the outcomes at maturity for the underlying asset. This assumption may hold for some efficiently traded financial securities but may not hold for real investments that do not have existing markets, or have inefficient markets, in which traded prices fail to reflect all available information. The application of the Black-Scholes or binomial option pricing method would be particularly problematic in health care, in which costs and benefits are typically non-normally distributed and often incomplete, therefore violating 2 critical conditions of the replicating portfolio process. ${ }^{24}$ A recently developed real option pricing method, the Datar-Mathews method (DMM), is based on simulation-generated probability distributions for the NPV of future project outcomes. The DMM shows that the real option value can be understood as the probability-weighted average of the payoff distribution. It is proposed that the probability distribution of the project is generated with a Monte-Carlo simulation. ${ }^{25}$ As an example, by drawing a large number of pseudorandom uniform variables from the interval $(0,1)$, and assigning values 0.50 as heads and $>0.50$ as tails, behavior of repeatedly tossing a coin is a Monte-Carlo simulation. The main issue with the use of Monte-Carlo simulations to inform the payoff distribution of innovative health care interventions is related to the relatively uninformative nature of the initial NPV scenarios, in which only the most likely or representative outcomes are likely to be modeled.

All of the aforementioned models use probability theory in their treatment of uncertainty, but there are also other ways (other than probability) to treat uncertainty or imprecision in future estimates. The fuzzy payoff method is similar to the probability theory based on the DMM, but the real option value can be derived from the NPV without any simulation. A fuzzy number is an extension of a regular number in the sense that it does not refer to 1 single value but rather to a connected set of possible values, in which each possible value has its own weight between 0 and 1 . Thus, fuzzy numbers can be used to formalize inaccuracy that exists in human decision making and as a representation of vague, uncertain, or imprecise knowledge (eg, future cash flow estimations). The fuzzy payoff method is described in depth in the Methods section, but its intuitive advantage over the commonly used financial models is that there is no need to estimate uncertainty from simulations. ${ }^{26}$ The real option value is calculated as the mean of the positive side of the fuzzy number. The main features and characteristics of the option pricing method described here are reported in Table I.

In summary, the valuation of 4 different HPV vaccination strategies can be formalized as a real option valuation, because:

1. There is an option embedded in the investment decision: management actions and decisions made during the life of the investment are valuable because they can push the payoff of the initial investment closer to its upper possible threshold, rather than accept a probabilistic mean value.

2. The real option is likely to have a significant economic value: the payer (the Italian NHS) has market exclusivity regarding implementation of the HPV vaccination.

3. The real option value can be estimated by using an option pricing method: the newly developed fuzzy payoff method seems to present a distinct advantage over the probability theory-based algorithms, such as the Black-Scholes method, the binomial method, or the DMM, related to its approach to uncertainty. The fuzzy payoff method minimizes the number of inferences related to the determinants of option value; consequently, it also minimizes the need for inference incumbent on the valuation of an innovative intervention in health care. $^{27}$

\section{The Payoff Method}

Fuzzy set theory is an extension of classical set theory, a logic based on 2 truth values (true and false). Fuzzy logic uses the full interval between 0 (false) and 1 (true) to describe human reasoning. A fuzzy set is any set that allows its members to have different 
Table I. Brief description of real option pricing models presented in the paper.

\begin{tabular}{|c|c|c|c|}
\hline Model & $\begin{array}{l}\text { Process to create future } \\
\text { value discribution }\end{array}$ & Distribution type & $\begin{array}{l}\text { Discounting of the } \\
\text { expected value }\end{array}$ \\
\hline Black \& Scholes (1973) & $\begin{array}{l}\text { Geometric Brownian } \\
\text { Motion }\end{array}$ & $\begin{array}{l}\text { Continuous log-normal } \\
\text { probability distribution }\end{array}$ & $\begin{array}{l}\text { Continuous discounting } \\
\text { with risk free }\end{array}$ \\
\hline Binomial (1979) & Binomial tree process & $\begin{array}{l}\text { Quasi log-normal } \\
\text { probability distribution }\end{array}$ & $\begin{array}{l}\text { Compound discounting } \\
\text { with risk free }\end{array}$ \\
\hline Datar-Mathews (2004) & $\begin{array}{l}\text { Cash flow scenarios and } \\
\text { Monte-Carlo }\end{array}$ & $\begin{array}{l}\text { Probability distribution of } \\
\text { various shapes }\end{array}$ & Flexible, user selectable \\
\hline Fuzzy pay-off method (2009) & $\begin{array}{l}\text { Cash flow scenarios } \\
\rightarrow \text { creation of fuzzy } \\
\text { number }\end{array}$ & Fuzzy number & Flexible, user selectable \\
\hline
\end{tabular}

degrees of membership, called membership function, in the interval $(0,1)$. A fuzzy set $\mathrm{A}$ in $\mathrm{R}$ (real line) is defined to be a set of ordered pairs $\mathrm{A}=\left\{\left(x, \mu_{A}(x)\right) \mid x \in\right.$ $R$, where $\mu_{A}(x)$ is called the membership function for the fuzzy set. Then $x$ is called "not included" in the fuzzy set A if $\mu_{A}(x)=0$, while $x$ is called "fully included" if $\mu_{A}(x)=1$.

A fuzzy set $\mathrm{A}$ is called normal if there is at least 1 point $x$ on the real line $(x \in \mathrm{R})$ with $\mu_{A}(x)=1$, so that the fuzzy set A is nonempty. A fuzzy set A in $\mathrm{R}$ is convex if for every pair of points within the object, every point on the straight line segment that joins them is also within the set. A fuzzy number is a normal, convex fuzzy set whose referential set is the real numbers $\mathrm{X} \in \mathrm{R} .^{28}$

This method can be likened to the game The Price Is Right, a popular television show in which contestants compete to win cash and prizes by guessing the pricing of merchandise, with closer guesses being more correct and with the actual price being completely correct (mapping to 1 by the membership function). By replacing the nonfuzzy (or "crisp" in fuzzy terminology) numbers that are commonly used in financial models with fuzzy numbers, we embed the inaccuracy of our forecasts and projections into the models themselves, as they do not simplify uncertain distribution-like observations to a single point estimate that conveys the sensation of nouncertainty. The payoff method derives the real option value from the triangular payoff distribution of the project's NPV, which is treated as a triangular fuzzy number.
A triangular payoff distribution is created by using 3 NPV scenarios: (1) a base case scenario with the estimations of the most likely values for cost and benefits; (2) a worst case scenario, based on the lowest credible estimates for cost and benefits; and (3) a best case scenario, based on the highest credible estimates for cost and benefits.

The payoff method will not consider outcomes outside the minimum and maximum scenarios; therefore, the values included define the payoff distribution of the project's NPV, which is treated as a fuzzy number. The payoff method defines the triangular payoff distribution as a triangular fuzzy number by denoting the following: $a$ corresponds to the base case mean NPV value; a represents the distance between a and the minimum possible NPV value; and $\beta$ is the distance between $a$ and the maximum possible NPV value.

By using these methods, we can denote the triangular payoff distribution that is a triangular fuzzy number as $(a, \alpha, \beta)$. The highest possibility (fully possible) is assigned to the base case and the lowest (near-zero) possibility to the minimum $(a-\alpha)$ and the maximum $(a+\beta)$ values of the distribution. The result is thus a triangular fuzzy distribution (A) that is equivalent to the fuzzy NPV of the project. The height of the payoff distribution reflects the degree of membership of each value of the distribution in the set of possible values for the NPV of the investment (Figure 1).

Looking at the payoff distribution, we observed that the mean value of the positive values of the fuzzy 


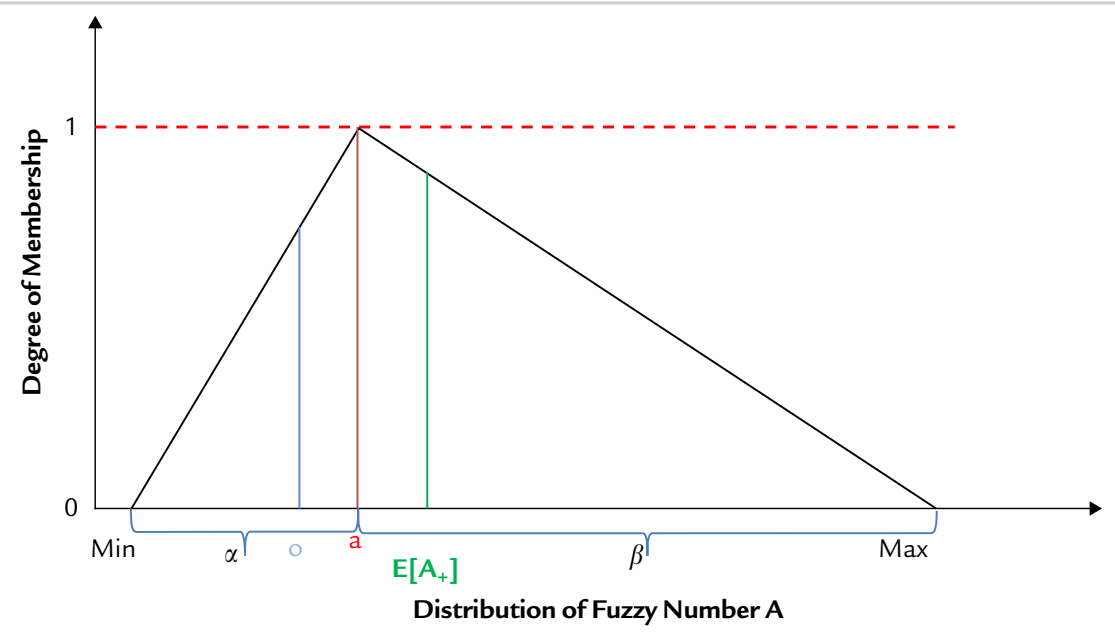

Figure 1. Triangular distribution of fuzzy set $A$. The fuzzy set $A$ is defined by 3 values: a (the best-case scenario [net present value (NPV)]), $\alpha$ (the distance between the minimum and the best case scenario NPV), and $\beta$ (the distance between the maximum and the best-case scenario). The area between a and $\alpha$ represents the distribution of all possible negative NPV values whereas the opposite side, between 0 and a $+\beta$, shows the distribution of positive NPV values. The mean value of the positive fuzzy NPV values $\boldsymbol{E}\left(\boldsymbol{A}_{+}\right)$is the fuzzy mean value of the NPV. Min = minimum; Max $=$ maximum.

$\mathrm{NPV}, \mathrm{E}\left(\mathrm{A}_{+}\right)$, is the mean value of the positive fuzzy NPV values. ${ }^{29}$

Based on the triangular fuzzy number arithmetic, $\mathrm{E}\left(\mathrm{A}_{+}\right)$is calculated as shown here ${ }^{30}$ : of the payoff distribution. This way of calculation is aligned with the real option valuation method, which implies that management will interrupt or modify a program when its payoff becomes negative.

$$
E\left(A_{+}\right)=\left\{\begin{array}{lll}
a+\frac{\beta-\alpha}{6}, & \text { if } 0<a-\alpha & \text { 'all NPV positive' } \\
\frac{(\alpha-a)^{3}}{6 \alpha^{2}}+a+\frac{\beta-\alpha}{6}, & \text { if } a-\alpha<0<a & \text { 'some negative NPV; positive peak' } \\
\frac{(\alpha-\beta)^{3}}{6 \beta^{2}} & \text { if } a<0<a+\beta & \text { 'some positive NPV; negative peak' } \\
0, & \text { if } a+\beta<0 & \text { 'all NPV negative' }
\end{array}\right.
$$

The real option value calculated from the fuzzy NPV is the mean value of the positive fuzzy NPV values $\mathrm{E}\left(\mathrm{A}_{+}\right)$multiplied by the positive area of the fuzzy NPV over the total area of the fuzzy NPV.

$$
\text { Real option valuation }=\frac{\int_{0}^{\infty} A(x) \mathrm{dx}}{\int_{-\infty}^{\infty} A(x) \mathrm{dx}} \mathrm{E}\left(A_{+}\right)
$$

In this equation, $A$ represents the fuzzy NPV, $E\left(A_{+}\right)$is the mean of the positive area of the payoff distribution, $\int_{0}^{\infty} A(x) \mathrm{dx}$ is the positive area of the payoff distribution, and $\int_{-\infty}^{\infty} \mathrm{A}(x) \mathrm{dx}$ is the whole area

\section{Sources of Data}

To inform the real option model, cost-effectiveness data were derived from an empirically calibrated Bayesian model designed to assess the costeffectiveness of a multi-cohort HPV vaccination strategy in the context of the current cervical cancer screening program in Italy. The model, developed to predict (for a 90-year period) the health benefits and economic consequences of a quadrivalent vaccination of 2, 3, and 4 cohorts of girls and women, has been previously described. ${ }^{31}$ 
Table II. Incremental cost-effectiveness ratio (ICER) per quality-adjusted life year (QALY) gained for a multicohort vaccination strategy. Data are given in Euros.

\begin{tabular}{lcccc}
\hline & & & & 4 Cohorts \\
Parameter & 1 Cohort & 2 Cohorts & 3 Cohorts & $(12,15,18$, and \\
& $(12$ years $)$ & $(12$, and 15 years $)$ & $(12,15$, and 18 years $)$ & 21 years $)$ \\
\hline ICER (mean) & 10,955 & 12,013 & 13,232 & 15,890 \\
$5 \%$ & $-1,021$ & 2,364 & 4,432 & 7,179 \\
$95 \%$ & 28,212 & 22,481 & 22,939 & 25,139
\end{tabular}

Probabilities with which patients move across the states were constructed by using a set of clinical data, demographic statistics, and time-dependent characteristics of HPV infection and related induced diseases. All unknown quantities (model parameters) were associated with plausible probability distributions that reflect the state of science currently available. These distributions were updated by using the relevant available data, and uncertainty was propagated through the entire model via a Markov chain Monte-Carlo procedure.

The Bayesian model was used to assess the costeffectiveness of a multi-cohort HPV vaccination strategy on the basis of a simulation of a large number of possible future scenarios under probabilistic assumptions. These simulations were used to derive a complete posterior distribution of outcomes, adopting the NHS perspective. Among other summaries, the assessment was performed by determining the ICER and the quality-adjusted life-years (QALYs) gained. The outcomes of the standard cost-effectiveness analysis are reported in Table II.

\section{The Real Option Model}

Because none of the $4 \mathrm{HPV}$ vaccination strategies evaluated is expected to be cost saving, any NPV scenario calculated by deducting vaccination costs from an estimate of costs avoided will be negative; consequently, the real option value of each strategy is zero.

However, such an approach would not capture the perspective of the Italian NHS, which is willing to fund health interventions priced in the range of $€ 20,000$ to $€ 40,000$ per QALY gained.

To calculate the expected fuzzy NPV for each of the 4 vaccination strategies evaluated, we used a net health benefit approach. ${ }^{27}$ In essence, a credible range of ICER per QALY was deducted from a commonly accepted range of values representing good value for money: this difference is ultimately a measure of the value created for public welfare expressed in monetary terms.

For each vaccination strategy, the mean ICER was deducted from a commonly accepted value for money (€30,000 per QALY gained) to obtain the middle value of the fuzzy NPV distribution. The upper value of the fuzzy NPV distribution was obtained by deducting the discounted (present) value (PV) of the lowest cost estimate [5\% Confidence Interval (CI) of ICER] from the highest value for money considered (€40,000 per QALY gained), while the lowest value was obtained by deducting the PV of the highest cost estimate (95\% CI of ICER) from the PV of the lowest acceptable level of value for money (€20,000 per QALY). Graphical representations of the payoff distributions of the $4 \mathrm{HPV}$ vaccination strategies are shown in Figure 2.

All of the 4 payoff distributions evaluated resulted partly above zero; therefore, zero was between the minimum possible NPV value and the base case NPV value, a was above zero, but a $-\alpha$ was below zero. The formula used to estimate the mean value of the positive distribution $E\left(A_{+}\right)$was $^{32}$ :

$$
E\left(A_{+}\right)=\frac{(\alpha-a)^{3}}{6 \alpha^{2}}+a+\frac{\beta-\alpha}{6}
$$

\section{RESULTS}

The outcomes of the standard cost-effectiveness analysis allow us to conclude that all the vaccination strategies may be considered as cost-effective interventions. The ICERs per QALY gained remained below the cutoff point of $€ 20,000$ to $€ 40,000$ adopted as a benchmark of good value for money from the perspective of the Italian NHS (Table II). 


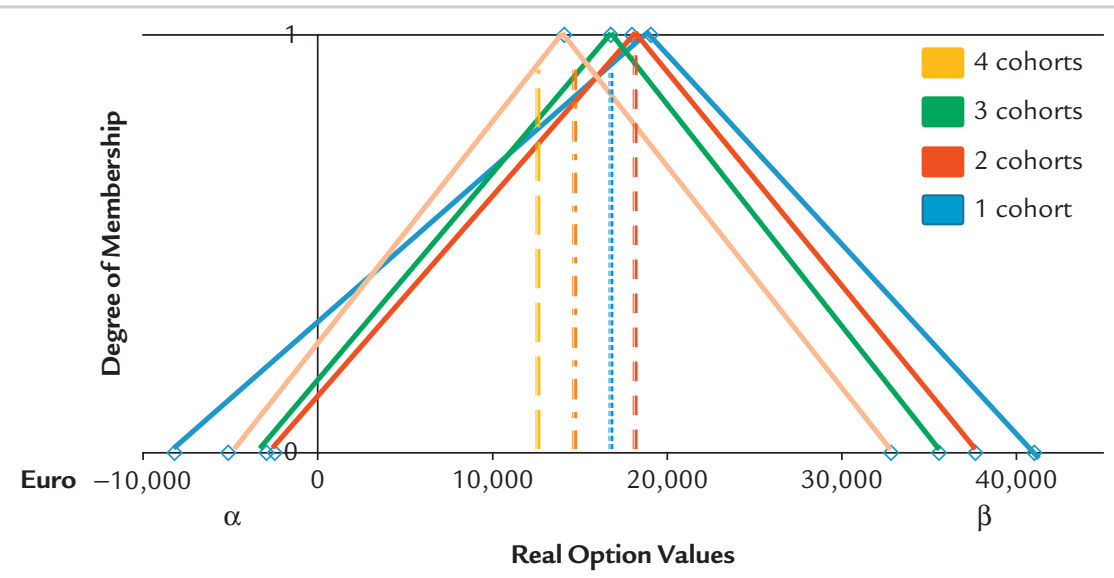

Figure 2. Pay-off distribution of the $4 \mathrm{HPV}$ vaccination strategies evaluated in the real option valuation. The left-hand side of the distribution shows the distance $(\alpha)$ between the minimum net present value (NPV) and the base-case scenario NPV (a) for the 4 vaccination options evaluated, as identified in the data legend located in the upper right-hand corner of the graph. The right-hand side of the distribution reports the distance $(\beta)$ between the maximum NPV value and the base-case scenario NPV (a). The dotted lines in the center of the distribution show the real options value for each option, which is the mean value of the positive fuzzy NPV values multiplied by the positive area of the fuzzy NPV over the total area of the fuzzy NPV. The highest real option value ( $€ 17,723$ [red dotted line]) was attributed to the 2 -cohort vaccination, followed by the single-cohort ( $€ 17,461$ [blue dotted line]), and, more distantly, by the 3-cohort (green dotted line) and 4-cohort (orange dotted line) cohort vaccination ( $€ 16,440$ and $€ 13,576$, respectively).

The cost per QALY gained seemed to be related to the number of cohorts targeted: the mean ICER per QALY gained for a single cohort of girls aged 12 years (€10,955 [95\% CI, $-1,021$ to 28,212$]$ ) was the lowest compared with all the alternative strategies. A sensitivity analysis of the cost-effectiveness model showed that with a probability of cost-effectiveness of $80 \%$, the cost per QALY gained remained below the range of threshold values for all the vaccination strategies evaluated.

The outcomes of real option valuation reported in Table III seem to show a different result. The highest real option value $(€ 17,723)$ was attributed to the 2cohort vaccination strategy, although the single-cohort strategy showed a similar real option value $(€ 17,460)$. Similarly to the standard cost-effectiveness analysis, the 3- and 4-cohort strategies showed lower real option values ( $€ 16,439$ and $€ 13,577$, respectively).

The substantial equivalence of the real option value for the 1- and 2-cohort strategy was confirmed when the boundaries of good value for money were shifted to higher rates, between $€ 30,000$ and $€ 45,000$, which is the same as the benchmark used in the cost-effectiveness acceptability curves. This time, however, it was the single-cohort strategy that produced the highest real option value $(€ 25,655)$, followed closely by the 2 -cohort $(€ 25,351)$, and further behind, by the 3-cohort (€24,117) and 4-cohort $(€ 21,520)$ immunization strategies.

\section{DISCUSSION}

The common approach by decision makers when deciding whether to invest in a national vaccination program is to determine whether the cost incurred by society of gaining a QALY is less than the amount accepted to represent an intervention worthy of implementation, which is commonly set at less than $€ 40,000$ per QALY. A further possible element for discussion is that of the choice of a single- or multicohort approach to immunization and the implications for disease prevention of vaccinating different age cohorts. ${ }^{33}$ Although the outcomes of the Bayesian model reported in the cost-effectiveness analysis could not be directly compared with any previous evaluation, the range of incremental cost per QALY gained for a single cohort of girls aged 12 years confirmed the costeffectiveness dominance of immunizing this cohort compared with the alternative strategies. 
Table III. Real option valuation of a multicohort vaccination strategy using the payoff method. Data are given in Euros, unless otherwise indicated.

\begin{tabular}{|c|c|c|c|c|}
\hline Parameter & $\begin{array}{l}1 \text { Cohort } \\
(12 \text { years })\end{array}$ & $\begin{array}{l}2 \text { Cohorts } \\
(12, \text { and } \\
15 \text { years })\end{array}$ & $\begin{array}{c}3 \text { Cohorts } \\
(12,15, \text { and } \\
18 \text { years })\end{array}$ & $\begin{array}{c}4 \text { Cohorts } \\
(12,15,18, \text { and } \\
21 \text { years })\end{array}$ \\
\hline \multicolumn{5}{|l|}{ Threshold value per $Q A L Y$ gained } \\
\hline Mean & 30,000 & 30,000 & 30,000 & 30,000 \\
\hline Minimum & 20,000 & 20,000 & 20,000 & 20,000 \\
\hline Maximum & 40,000 & 40,000 & 40,000 & 40,000 \\
\hline \multicolumn{5}{|l|}{ Cost } \\
\hline ICER (mean) & 10,955 & 12,013 & 13,232 & 15,890 \\
\hline $5 \%$ & $-1,021$ & 2,364 & 4,432 & 7,179 \\
\hline $95 \%$ & 28,212 & 22,481 & 22,939 & 25,139 \\
\hline \multicolumn{5}{|l|}{ Fuzzy $(N P V) s$} \\
\hline a: the 'base case' NPV value & 19,045 & 17,987 & 16,768 & 14,110 \\
\hline Minimum NPV value & $-8,212$ & $-2,481$ & $-2,939$ & $-5,139$ \\
\hline Maximum NPV value & 41,021 & 37,636 & 35,568 & 32,821 \\
\hline \multicolumn{5}{|l|}{ Triangular fuzzy distribution (A) } \\
\hline $\begin{array}{l}\alpha: \text { the distance between } a \text { and the } \\
\text { minimum NPV value }\end{array}$ & 27,257 & 20,468 & 19,707 & 19,249 \\
\hline $\begin{array}{l}\beta \text { : the distance between a and the } \\
\text { maximum possible value }\end{array}$ & 21,976 & 19,649 & 18,800 & 18,711 \\
\hline $\begin{array}{l}E(A+) \text { : the fuzzy mean value of } \\
\text { the positive side of }(A)\end{array}$ & 18,375 & 17,857 & 16,629 & 14,085 \\
\hline Positive area of $\mathrm{A}$ (\% of total) & $95.02 \%$ & $99.25 \%$ & $98.86 \%$ & $96.39 \%$ \\
\hline Real option value & 17,460 & 17,723 & 16,439 & 13,577 \\
\hline
\end{tabular}

ICER $=$ incremental cost-effectiveness ratio; NPV $=$ net present value; $\mathrm{QALY}=$ quality-adjusted life-year.

To reduce the shortcomings of a standard costeffectiveness paradigm, for the first time we applied a real option model to the economic evaluation of a multicohort HPV vaccination strategy. As with costeffectiveness analysis, the real option approach involves projecting future streams of costs and economic benefits, but its paradigm assumes that managers can influence the outcome by interventions that add value over time. ${ }^{34}$ The 4 strategies evaluated represent alternative options available to policy makers, the value of which may be determined by application of the payoff method with the aim of identifying the vaccination strategy that embeds the highest real option value.

The method uses fuzzy numbers to determine the distribution of the expected values of a given intervention. By taking into account only the positive side of the distribution in the real option value, the payoff method explicitly recognizes the ability of managers to interrupt the intervention as soon as its NPV becomes negative and thus avoid further losses. The different approach to uncertainty and the recognition of the economic value of the active role of management differentiate the payoff pricing method for real options from the cost-effectiveness paradigm.

The real option pricing of the $4 \mathrm{HPV}$ vaccination strategies evaluated here offers new insights into the implementation of a national immunization program from the perspective of the NHS. The payoff method assigned the highest real option value to the 2-cohort strategy $(€ 17,723)$, closely followed by the singlecohort option $(€ 17,460)$. The substantial equivalence of the 2 leading options in terms of value created is not irrelevant in the choice of the vaccination strategy, in the absence of other noneconomic considerations. 
There are 3 reasons why a single-cohort strategy may not be preferable, however. First, less time would be required to reduce HPV-related outcomes by using a multicohort vaccination program than by the vaccination of a single cohort of 12-year-old girls. In particular, the clinical benefits of vaccination, especially the prevention of low-grade cervical intraepithelial neoplasia and anogenital warts, would be expected to occur 3.8 years earlier with a 2-cohort strategy. ${ }^{31}$ Second, access to the HPV vaccination program would be doubled by adding 272,387 girls aged 15 years to the 12-year-old cohort $(272,791$ girls). ${ }^{35}$ Increasing vaccination coverage in girls aged $<14$ years may be expected to reduce the incidence of cervical cancer. ${ }^{36}$

Lastly, a vaccination program that includes both boys and girls can be considered to be a 2-cohort strategy. In light of the results of the real option evaluation, involvement of both girls and boys aged 12 years in a national HPV program should be reconsidered. Our review of the multicohort HPV vaccination strategy established that the application of real option valuation requires a careful consideration of cost-effectiveness scenarios to identify relevant developments in the external environment and their impact on the value of the options.

Although cost-effectiveness analysis focuses on the impacts of external factors that are usually beyond the control of management, real option analysis creates a "space" for decision making. It engages management in a better understanding of the value consequences of different networks of choice than would be afforded by cost-effectiveness analysis. ${ }^{37}$ As opposed to the nonlinear pathway of value determined at any given time by cost-effectiveness analysis, which fixes the mind on whether to implement a program, real option analysis affords value-improving benefits in terms of the opportunities for choice created by such thinking. ${ }^{38}$

Although the Bayesian framework adopted here provided credible estimates of the cost-effectiveness of each vaccination strategy, the choice of the costeffectiveness economic outcomes to inform the real option analysis represented the main limitation of this analysis. The fuzzy NPV is a distribution of the possible value that can take place for NPV; thus, outcomes perceived as impossible at the time of the cost-effective analysis are not included in the real option valuation. Extreme tails should be included in the real option analysis, because even low-probability outcomes should be taken into consideration. Second, the costeffectiveness analysis of the multicohort HPV vaccination strategy did not take into account the effect of herd immunity, hence potentially underestimating the costeffectiveness of multicohort vaccination strategies. ${ }^{39}$ Moreover, the outcomes of the dynamic model should have been compared with those of a static model because the severity of disease state and age may lead to a more favorable estimate of cost-effectiveness than the use of a dynamic approach. ${ }^{40}$

\section{CONCLUSIONS}

The real option valuation of a multicohort HPV vaccination strategy challenges the accepted dominance of cost-effectiveness for a single cohort of 12year-old girls. The simultaneous vaccination of 2 cohorts of girls aged 12 and 15 yielded a real option value $(€ 17,723)$ equivalent to that attributable to a single cohort of 12 -year-old girls $(€ 17,460)$. Although all 4 vaccination strategies considered here showed a positive real option value, a national vaccination program targeting 2 cohorts should be the implementation method of choice when the impact on access, coverage, and, ultimately, time to prevention of HPVinduced diseases is taken into account. Although national anti-HPV immunization programs have already been initiated in most European Union countries, the outcomes of real option analysis suggest that policy makers should reassess the value created by a 2cohort HPV vaccination program targeting boys and girls 12 years of age.

Generalizing the outcomes of our discussion, we should conclude that the payoff method showed 4 distinctive advantages in the valuation of the costeffectiveness of health care interventions. First, the fuzzy payoff method uses expert-generated cash flow scenarios as an input to inform the real option pricing method. This method allows for the process of future value distribution to include information that is outside the flexibility offered by probabilities-centered methods, such as hedging strategies to reduce risk, subjective probability to shape uncertainty, and game theory to include the economic effect of market competition on the valuation. Second, although the main output of a cost-effectiveness model is a relative measure of cost, real options are expressed in terms of value attributed to welfare. This difference is not semantic; to be better understood by policy makers and more easily communicated to society, economic evaluations should focus on 
the value of the benefits delivered by health programs rather than their cost. Third, the fuzzy payoff method derives the real option value simply as the mean of the positive side of the fuzzy number. Its intuitive advantage over the commonly used financial models is that there is no need to estimate uncertainty from distribution-like observations. By doing so, the fuzzy payoff method moves away from probabilistic calculus to create a triangular future value distribution that is treated as a fuzzy number. Lastly, as with NPV analysis, the payoff perspective involves projecting future cash flows and choosing an appropriate discount rate. However, unlike NPV analysis, the payoff method assumes managers can influence the outcome by making a series of successive decisions ("options") that add value over time. The merit of the real option approach to value uncertainty is appealing: it makes policy making in health care an evolutionary process, flexibly moving from 1 choice point to the next through time and creating a new "space" for decision-making choices.

\section{ACKNOWLEDGEMENTS}

Giampiero Favato developed the real option model used in the study. All authors contributed equally to the data collection, data interpretation, writing and revision of the paper.

\section{CONFLICTS OF INTEREST}

In the past 3 years, Dr. Capone has been a consultant of Sanofi Pasteur MSD Italy, which markets Gardasil, an anti-HPV vaccine. This relationship did not alter the authors' adherence to all policies of the Journal regarding sharing data and materials. The authors have indicated that they have no other conflicts of interest regarding the content of this article.

\section{REFERENCES}

1. Descriptive Epidemiology Group of International Agency for Research on Cancer (IARC). Cancer Incidence, Mortality and Prevalence Worldwide-GLOBOCAN 2008.: http://www-dep.iarc.fr. Accessed October 10, 2013.

2. Walboomers JM, Jacobs MV, Manoss MM, et al. Human papillomavirus is a necessary cause of invasive cervical cancer worldwide. J Pathol. 1999;189:12-19.

3. Bosch FX, Iftner T. The Aetiology of Cervical Cancer. NHS Cancer Screening Programmes (NHSCSP). http://www.cancer screening.nhs.uk/cervical/publications/nhscsp22.html. Accessed June 3, 2013.
4. Bosch FX, Lorincz A, Muñoz N, et al. The causal relation between human papillomavirus and cervical cancer. J Clin Pathol. 2002;55:244-265.

5. Sanders GD, Taira AV. Cost effectiveness of a potential vaccine for human papillomavirus. Emerging Infect Dis. 2003;9:37-48.

6. Kulasingam SL, Myers ER. Potential health and economic impact of adding a human papillomavirus vaccine to screening programmes. JAMA. 2003;290:781-789.

7. Taira V, Neukermans CP, Sanders GD. Evaluating human papillomavirus vaccination programmes. Emerging Infect Dis. 2004;10:1915-1923.

8. Goldie SJ, Kholi M, Grima D, et al. Projected clinical benefits and cost effectiveness of a human papillomavirus 16/18 vaccine. J National Cancer Institute. 2004;96: 604-615.

9. Barnabas RV, Laukkanen P, Koskela P, et al. Epidemiology of HPV 16 and cervical cancer in Finland and the potential impact of vaccination: mathematical modelling analyses. PLoS Med. 2006;3:624-632.

10. Elbasha EH, Dasbach EJ, Insinga RP. Model for assessing human papillomavirus vaccination strategy. Emerging Infect Dis. 2007;13:28-41.

11. Kim JJ, Goldiee SJ. Health and economic implications of HPV vaccination in the United States. N Engl J Med. 2008;359:821-832.

12. Jit $M$, Choi $\mathrm{YH}$, Edmunds WJ. Economic evaluation of human papillomavirus in the United Kingdom. BMJ. 2008;337:a769.

13. Mennini FS, Giorgi Rossi P, Palazzo F, et al. Health and economic impact associated with a quadrivalent HPV vaccine in Italy. Gynaecological Oncol. 2009;112:370-376.

14. Mennini FS, Costa S, Favato G, et al. Anti-HPV vaccination: a review of recent economic data for Italy. Vaccine. 2009;27:A54-A61.

15. Drummond $M$, Chevat $C$, Lothgren $M$. Do we fully understand the economic value of vaccines? Vaccine. 2007;25:5945-5957.

16. McKinsey \& Co, Koller T, Goedhart M, Wessels D. Valuation: Measuring and Managing the Value of Companies Fifth Edition. Hoboken, NJ: Wiley Finance; 2010.

17. Mills RW, Weinstein WL, Favato G. Using scenario thinking to make real options relevant to managers: a case illustration. J General Management. 2006;31:49-74.

18. Myers SC. Determinants of corporate borrowing. J Financial Econ. 1977;5:147-175.

19. Carlsson C, Fullér R. On possibilistic mean value and variance of fuzzy numbers. Fuzzy Sets Systems. 2001; 122:315-326.

20. Damodaran A. The promise of real options. J Applied Corporate Finance. 2000;13:29-44.

21. Mennini FS, Baio G, Montagano G, et al. Governance of preventive health intervention and on time verification of 
its efficiency: the GIOVE Study. BMJ Open. 2012;2:e000736.

22. Black F, Scholes M. The pricing of options and corporate liabilities. J Political Economy. 1973;81:637-654.

23. Cox J, Ross S, Rubisnstein M. Option pricing: a simplified approach.

J Financial Economics. 1979; 7:229-263.

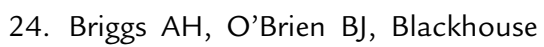
G. Thinking outside the box: recent advances in the analysis and presentation of uncertainty in costeffectiveness studies. Annual Review Public Health. 2002;23:377-401.

25. Datar V, Mathews S. European real options: an intuitive algorithm for the Black-Scholes formula. J Applied Finance. 2004;14:45-51.

26. Hanss M. Applied Fuzzy Arithmetic. An Introduction With Engineering Applications. Berlin, Germany: Springer-Verlag; 2005.

27. Stinnett AA, Mullhay J. Net health benefits. A new framework for the analysis of uncertainty in costeffectiveness analysis. Medical Decis Making. 1988;18:S68-S80.

28. Zadeh A. Fuzzy Sets*. Information and Control. 1965;8:338-353.

29. Collan M, Fuller R, Mezei J. A fuzzy pay-off method for real options valuation. J Applied Mathematics Decision Sciences. 2009;165-169.

30. Kinnunen J. Valuing M\&A synergies as (fuzzy) Real Options. 2010 Annual International Conference on Real Options, REALOPTIONS. http://www.realoptions.org/papers 2010/238.pdf. Accessed October 7, 2013.

31. Favato G, Baio G, Capone A, et al. Novel health economic evaluation of a vaccination strategy to prevent HPVrelated diseases: the BEST study. Med Care. 2012;50:1076-1085.

32. Collan M. The Pay-off Method: Reinventing Investment Analysis. Amazon. co.uk, 2012.

33. European Centre for Disease Prevention and Control (ECDC). Guidance for the introduction of HPV vaccines in EU countries. Guidance report,
Stockholm, January 2008. http:// ecdc.europa.eu/en/publications/ Publications/0801_GUI_Introduc tion_of_HPV_Vaccines_in_EU.pdf. Accessed June 3, 2013.

34. Anderson TJ. Real options analysis in strategic decision making: an applied approach in a dual options framework. J Applied Management Studies. 2000;9:235-255.

35. Istituto Nazionale di Statistica (ISTAT). GeoDemo: resident population in Italy 2011. http://demo. istat.it/. Accessed October 24, 2012.

36. Ribassin-Majed L, Lounes R, Clémençon S. Efficacy of vaccination against HPV infections to prevent cervical cancer in France: present assessment and pathways to improve vaccination policies. PLoS ONE. 2012;7:e32251.

37. Miller KD, Waller GH. Scenarios, real options and integrated risk management. Long Range Planning. 2003;36:93-107.

38. Dixit AK, Pindyck RS. The options approach to capital investment. Harvard Business Review. 1995;733: 105-116.

39. Brisson M, Edmunds WJ. Economic evaluation of vaccination programmes: the impact of herd immunity. Med Decis Making. 2003;23:76-82.

40. Brisson M, Edmunds WJ. Impact of model, methodological and parameter uncertainty in the economic analysis of vaccination programmes. Med Decision Making. 2006;26:434-446.
Address correspondence to: Giampiero Favato, DBA, Kingston Business School, Room 318, Kingston Hill, KT2 7LB Kingston-upon-Thames, United Kingdom. E-mail: g.favato@kingston.ac.uk 